\title{
GERMINAÇÃO DE SEMENTES DE Stryphnodendron adstringens (Mart.) Coville DE DIFERENTES ORIGENS SUBMETIDAS A TRATAMENTOS PARA SUPERAÇÃO DE DORMÊNCIA ${ }^{1}$
}

\author{
Cibele Chalita Martins² e João Nakagawa²
}

\begin{abstract}
RESUMO - Sementes de diferentes procedências podem apresentar variações na intensidade de dormência, respondendo de forma diferenciada aos tratamentos e dificultando a indicação da melhor metodologia para superá-la. Este trabalho teve o objetivo de identificar métodos para superar a dormência e promover a germinação de sementes de barbatimão de diferentes procedências. Sementes dessa espécie foram colhidas em sete fragmentos de Cerrado localizados na região de Botucatu, SP, e submetidas aos seguintes tratamentos de superação de dormência: testemunha, escarificação mecânica (lixa 220), $\mathrm{H}_{2} \mathrm{O}$ quente por 20 min e escarificação com $\mathrm{H}_{2} \mathrm{SO}_{4}(95 \%)$ por 40, 60 e $80 \mathrm{~min}$. As sementes foram avaliadas quanto ao teor de água, teste de germinação, comprimento de plântulas, índice de velocidade de germinação e condutividade elétrica. A escarificação em ácido sulfúrico por $60 \mathrm{~min}$ foi o tratamento mais eficiente para superar a dormência, acelerar e aumentar a porcentagem de germinação e resultar plântulas de maior tamanho, para as sementes de diferentes locais de origem.
\end{abstract}

Palavras-chave: Sementes duras, florestal e planta medicinal.

\section{GERMINATION OF Stryphnodendron adstringens (Mart.)Coville SEEDS FROM DIFFERENT SOURCES SUBMITTED TO DORMANCY BREAKING TREATMENTS}

\begin{abstract}
Seeds from different sources may present variation in dormancy intensity, responding differently to treatments and making it difficult to select the best dormancy breaking method. This work aimed to identify methods for breaking dormancy and promoting germination of Stryphnodendron adstringens seeds from differents origins. Seeds of Stryphnodendron adstringens were harvested at seven cerrado fragments in the Botucatu region $(S P)$ and were submitted to the following treatments for breaking dormancy: control, mechanical scarification (with sand paper 220), boiling water for 20 minutes and acid scarification (with $\mathrm{H}_{2} \mathrm{SO}_{4} 95 \%$ ) for 40, 60 and 80 minutes. Seeds were evaluated by water content, germination test, seedling length, and conductivity test. Scarification with sulphuric acid for 60 minutes was the most efficient treatment for breaking dormancy, accelerating and increasing germination percentage and resulting in seedlings with large size, for all the seeds from different origins.
\end{abstract}

Keywords: Hard seed, medicinal plant and forest seed.

\section{INTRODUÇÃO}

Stryphnodendron adstringens (Mart.) Coville (Leguminosae-Mimosoideae), conhecida como barbatimão, é uma árvore com ocorrência predominante em cerrados dos Estados brasileiros como Pará, Minas Gerais, São Paulo, Mato Grosso do Sul e o Distrito Federal (LORENZI, 1992; FELFILI e SILVA JÚNIOR,
1993; FELFILI et al., 1999). Pode ser utilizada para a extração da madeira, que é pesada, dura e resistente à ação da água e do sol. A casca do barbatimão possui alto teor de tanino e é utilizada na medicina popular devido à sua ação adstringente. Também é uma espécie indicada para a recuperação de áreas degradadas (LORENZI, 1992).

\footnotetext{
${ }^{1}$ Recebido em 03.08.2007 e aceito para publicação em 22.08.2008.

${ }^{2}$ Departamento de Produção Vegetal da Universidade Estadual Paulista Júlio de Mesquita Filho (UNESP). E-mail : <cibele@ fca.unesp.br>
} 
A dispersão de $S$. adstringens ocorre por meio de sementes que apresentam dormência, de modo similar ao verificado em $S$. pulcherrimum (Willd.) Hochr. (VARELA et al., 1991) e S. polyphyllum Mart. (LEMUS FILHO et al., 1997). A dormência das sementes é uma estratégia de sobrevivência que permite à espécie superar condições ambientais desfavoráveis, como o fogo e os períodos de seca, que são comuns nas áreas de Cerrado na época de frutificação e dispersão das sementes de barbatimão (FELFILI et al., 1999). Mas essa característica é problema quando se pretende a produção de mudas em viveiro, pois causa atraso e desuniformidade na germinação.

Na família Leguminosae, subfamília Mimosoideae, a causa de dormência mais comum é a decorrente da impermeabilidade do tegumento (CARVALHO e NAKAGAWA, 2000). A dureza do tegumento é atribuída à camada de células em paliçada, que apresenta paredes espessas e recobertas externamente por uma camada cerosa (POPINIGIS, 1985). Existem vários tratamentos que podem ser usados com êxito para romper o tegumento e superar esse tipo de dormência, como: escarificação mecânica por abrasão (VARELA et al., 1991; NUNÕ, 1995; LEMUS FILHO et al., 1997; ALVES et al., 2000; BRUNO et al., 2001); escarificação química com $\mathrm{H}_{2} \mathrm{SO}_{4}$ (VARELA et al., 1991; EIRA et al., 1993; NUNÕ, 1995; ALVES et al., 2000; BORGES et al., 2004; ALVES et al., 2006); e embebição em água quente (EIRA et al., 1993; NUNÕ, 1995).

Em viveiros, a imersão em água quente é o método de superação de dormência mais utilizado, por oferecer menor risco de queimaduras aos trabalhadores que o ácido sulfúrico, menor custo e permitir o tratamento de volumes maiores de sementes que a escarificação mecânica por abrasão. No entanto, para muitas espécies a escarificação química com ácido sulfúrico ou a mecânica com lixa é mais eficiente. Esta última é utilizada como tratamento de referência em trabalhos de superação de dormência de sementes com tegumento impermeável (CARVALHO e NAKAGAWA, 2000; ALVES et al., 2000).

O tempo de aplicação e a eficiência dos tratamentos de superação de dormência dependem da espécie (BRASIL, 1992) e das características intrínsecas de cada lote de sementes (EIRA et al., 1993; NUNÕ, 1995; BRUNO et al., 2001; BORGES et al., 2004). Dessa forma, sementes de diferentes procedências podem apresentar variações na intensidade de dormência (EIRA et al.,
1993; NUNÕ, 1995; CARVALHO e NAKAGAWA, 2000; BORGES et al., 2004). Portanto, podem responder de forma diferenciada aos tratamentos, dificultando a indicação da melhor metodologia para superá-la. Provavelmente, esse seria um motivo para que alguns trabalhos apresentem resultados conflitantes quanto à eficiência de determinado método de superação de dormência para sementes de uma mesma espécie.

Assim, Eira et al. (1993), em estudo com quatro lotes de Enterolobium contortisiliquum (Vell.) Morong., constataram que a imersão em água quente promoveu a superação da dormência de um lote, fazendo que a porcentagem de germinação inicial de $0 \%$ atingisse valores acima de $90 \%$. Já outros dois lotes apresentaram aumento na porcentagem de germinação, embora sem diferença estatística, o último lote não respondeu ao tratamento e as sementes, em sua quase totalidade, permaneceram dormentes. No entanto, a escarificação com ácido sulfúrico mostrou-se eficiente na superação da dormência das sementes em todos os lotes avaliados.

Borges et al. (2004) também identificaram comportamento variável das sementes de Tachigalia multijuga, oriundas de três matrizes, aos tratamentos de superação de dormência. Nas sementes de uma delas somente o ácido sulfúrico por $20 \mathrm{~min}$ possibilitou a germinação máxima, enquanto nas outras duas os despontes também foram eficientes.

Nuño (1995), em estudo com 10 lotes de Leucaena leucocephala de diferentes procedências, observou que os lotes comportaram-se de forma diversa ao método de superação de dormência, havendo um de sementes recém-colhidas em que o tratamento com água quente, em comparação com a testemunha, sem tratamento, passou de $14 \%$ de germinação para $78 \%$, enquanto outro de $16,5 \%$ passou para $38 \%$. Mas, de forma geral, a escarificação manual apresentou melhores resultados em todos os lotes, seguida em eficiência pelo ácido sulfúrico e pela escarificação mecânica. Os resultados dos trabalhos de Borges et al. (2004) e Nuño (1995) indicaram que se devem procurar métodos que sejam eficientes na superação da dormência tegumentar, independentemente da procedência do lote.

Verificou-se, portanto, a necessidade de novas pesquisas enfocando metodologias para superação de dormência de sementes de espécies florestais, fazendo o uso do maior número de progênies possível, para que possam ser aplicadas com maior chance de êxito. 
Este trabalho objetivou identificar métodos para superar a dormência e promover a germinação de sementes de barbatimão procedentes de vários fragmentos de Cerrado da região de Botucatu, SP.

\section{MATERIAL E MÉTODOS}

Os frutos de barbatimão foram colhidos em diversos fragmentos de Cerrado localizados na região de Botucatu, Estado de São Paulo, em um número mínimo de 10 plantasmãe por local de origem (lote), e transportados até o Laboratório de Análise de Sementes do Departamento de Produção Vegetal da Faculdade de Ciências Agronômicas da UNESP, onde as sementes foram extraídas manualmente das vagens e submetidas a uma limpeza, mediante a separação manual para a retirada de sementes chochas, malformadas e danificadas por fungos e insetos.

As coordenadas geográficas dos locais de coleta dos frutos de barbatimão, obtidas através de um GPS, são: lote 1 - Chácara Carlos Basso (2254`49,8”S; $\left.48^{\circ} 25^{\prime} 98,4^{\prime \prime} \mathrm{W}\right)$, lote 2 - Jardim Reflorenda (22 $54^{\circ} 66,6^{\prime \prime}$ 'S; 48²6'08,4'W), lote 3 - Convívio Paraná (2254'57,7's; $48^{\circ} 25^{\prime}$ '96, '”'W), lote 4 - Condomínio Nova Califórnia (2254'41,5'S; 48²8'51,4'W), lote 5 - Fazenda Demétria (22 57'39, 1'S; 48 24'35,3'W), lote 6 - Jardim Riviera (22'57'24,2''S; 48²4'58,2'W) e lote 7 - Fazenda Boa Vista (22059'02,6”S; 48²2'57,2”W).

Os tratamentos de superação de dormência utilizados foram os seguintes: testemunha (sementes sem tratamento), escarificação mecânica (fricção manual da semente no lado oposto ao eixo embrionário em lixa número 220), água em ponto de ebulição por $20 \mathrm{~min}$ (temperatura inicial do conjunto de aproximadamente $87^{\circ} \mathrm{C}$, seguida de secagem à sombra por 6 h), escarificação ácida por 40, 60 e 80 min (imersão das sementes em ácido sulfúrico 36 N, 95\%, pelo tempo previsto, seguida de lavagem em água corrente e secagem à sombra por $6 \mathrm{~h}$ ).

Após os tratamentos, as sementes foram avaliadas pelos testes descritos a seguir. Teor de água realizado antes da instalação dos demais testes e obtido por meio de duas subamostras de 20 sementes pelo método da estufa a $105 \pm 3{ }^{\circ} \mathrm{C}$ por $24 \mathrm{~h}$ (BRASIL, 1992). Teste de germinação - conduzido com quatro subamostras de 50 sementes em rolo de papel-toalha umedecido com duas vezes o peso do papel em água e colocadas para germinar sob temperatura de $25^{\circ} \mathrm{C}$ e $8 \mathrm{~h}$ de luz $\left(78 \mathrm{mmol} \mathrm{s}^{-1} \mathrm{~m}^{-2}\right)$, calculando-se as porcentagens de plântulas normais (germinação), anormais, sementes dormentes e mortas no $42^{\circ}$ dia após a semeadura (MARTINS et al., 2008). Primeira contagem da germinação - realizada aos quatro dias após a semeadura do teste de germinação, contabilizandose o número de plântulas normais (VIEIRAe CARVALHO, 1994). Índice de Velocidade de Germinação (IVG) - determinado por meio de adaptação do critério estabelecido por Maguire (1962), contabilizando-se semanalmente as sementes germinadas do sétimo ao $42^{\circ}$ dia da semeadura. Condutividade elétrica - avaliada através da medição da condutividade elétrica da solução de embebição das sementes, empregandose quatro repetições de 50 sementes por tratamento, cujas massas foram determinadas e colocadas em copos plásticos contendo $75 \mathrm{ml}$ de água destilada e deixadas para embeber a $25^{\circ} \mathrm{C}$ por $24 \mathrm{~h}$; decorrido esse período, a condutividade elétrica da solução foi determinada através de condutivímetro e os valores de cada repetição, expressos em $\mathrm{mS} \mathrm{cm}^{-1} \mathrm{~g}^{-1}$ de sementes (VIEIRA e CARVALHO, 1994). Comprimento de plântulas - avaliado por meio de quatro repetições de 10 sementes por tratamento colocadas para germinar a $25^{\circ} \mathrm{C}$ em rolos de papel-toalha umedecidos com duas vezes o peso do papel em água e dispostos verticalmente (VIEIRA e CARVALHO, 1994). A medição do comprimento da parte aérea (epicótilo-colo), da raiz primária (colomeristema radicular) e do comprimento total de plântulas foi realizado com régua aos 17 dias após a semeadura.

O experimento foi instaladoem delineamento estatístico inteiramente ao acaso e com quatro repetições e disposto em esquema fatorial $7 \times 5$, sendo sete lotes e cinco métodos de superação de dormência avaliados. As variáveis que apresentaram dados em porcentagem com valores nulos foram transformadas em $(x+0,5)^{1 / 2}(B A R B I N, 2003) e$ os demais dados, analisados sem transformação. As médias apresentadas são dos dados originais.

\section{RESULTADOS E DISCUSSÃO}

No Quadro 1, verifica-se que o teor de água médio dos lotes foi de $5,9 \%$, na testemunha. Os tratamentos de imersão em ácido sulfúrico por 40, 60 e 80 min foram os que apresentaram teor de água mais elevados após a sua aplicação, apresentando teores médios de 12,7; 11,1; e 11,0\%, respectivamente. Esses valores foram superiores ao do tratamento com lixa, que apresentou teor de água de 8,7\% e foi usado como referência por ser um tratamento de comprovada eficiência na superação da dormência de sementes com dureza tegumentar.

R. Árvore, Viçosa-MG, v.32, n.6, p.1059-1067, 2008 
Os teores de água mais elevados obtidos com a utilização de $\mathrm{H}_{2} \mathrm{SO}_{4}$ se deveram à maior permeabilidade do tegumento que favoreceu a entrada de água da semente. No caso do ácido sulfúrico, os dados de teor de água (Quadro 1) indicam que a lavagem das sementes em água realizada ao final do tratamento e a avaliação das sementes somente após $6 \mathrm{~h}$ de secagem ocasionaram a embebição. As sementes submetidas à lixa devem ter absorvido a umidade do ar durante o período transcorrido entre a aplicação do tratamento e a instalação do teste. O tratamento de imersão em água quente também favoreceu a entrada de água nas sementes, apresentando teores médios de $6,9 \%$, superiores ao da testemunha.

Em cada tratamento de superação de dormência, quando foram comparados os teores de água dos lotes, verificaram-se diferenças de 1,7 ponto porcentual (testemunha) até 3,2 pontos porcentuais (água quente), o que demonstra que os lotes apresentaram sementes com permeabilidades iniciais diferentes e que tais diferenças podem ser aumentadas, dependendo do método de superação de dormência empregado (Quadro 1).

Maiores valores de condutividade elétrica das sementes submetidas à escarificação com ácido sulfúrico, nos três tempos de imersão e com lixa, indicam que houve melhor condição de embebição e lixiviação de solutos, contrário à testemunha que não permitiu esse fato, resultando em baixos valores de condutividade devido ao tegumento impermeável (Quadro 2).

Os testes da primeira contagem e índice de velocidade de emergência (IVE) indicaram que os tratamentos com ácido sulfúrico e lixa aumentaram a velocidade de germinação. Para a quase totalidade dos lotes, o período de 40 min de imersão em ácido apresentou valores similares aos da escarificação com lixa; nos períodos de 60 a $80 \mathrm{~min}$, os resultados foram superiores em relação à lixa e aos demais tratamentos.

O tratamento de imersão em água quente não mostrou diferenças de resposta nos lotes 1 a 6 , quando comparados com a testemunha, quanto à condutividade elétrica e ao índice de velocidade de emergência. No entanto, no teste da primeira contagem alguns lotes (1, 2, 3 e 7) apresentaram desempenho superior em relação à testemunha, embora piores que a lixa e os tratamentos de escarificação em ácido.

Os tratamentos mais favoráveis à superação da dormência dos lotes avaliados foram os de imersão em ácido nos tempos de 40 até $80 \mathrm{~min}$, pois apresentaram porcentagens de sementes dormentes iguais ou inferiores à escarificação com lixa, que é um tratamento de referência, além de tornar zero a porcentagem de sementes dormentes da quase totalidade dos lotes (Quadro 3). Quanto à porcentagem de plântulas normais, esses tratamentos também foram os mais favoráveis, não diferindo do tratamento de escarificação mecânica com lixa.

Os tratamentos de imersão em ácido sulfúrico, nos lotes 2 e 3 (todos os tempos de imersão) e 5, na imersão por 80 min aumentaram significativamente a porcentagem de sementes mortas. Quanto a plântulas anormais, somente o lote 6 no tratamento de imersão em ácido sulfúrico por $80 \mathrm{~min}$ apresentou valores maiores que os da testemunha. A porcentagem de plântulas anormais e sementes mortas é utilizada para auxiliar a avaliação dos possíveis danos que os tratamentos poderiam causar às sementes e à identificação de sensibilidades diferenciadas dos lotes aos tratamentos (CARVALHO e NAKAGAWA, 2000).

Quadro 1 - Teor de água (\%) de lotes de sementes de Stryphnodendron adstringens após tratamentos de superação de dormência Table 1 - Moisture content (\%) of seed lots of Stryphnodendron adstringens after breaking dormancy treatments

\begin{tabular}{|c|c|c|c|c|c|c|}
\hline \multirow[t]{3}{*}{ Lotes } & \multicolumn{6}{|c|}{ Tratamentos de Superação de Dormência } \\
\hline & \multirow[t]{2}{*}{ Testemunha } & \multirow[t]{2}{*}{ Lixa } & \multirow{2}{*}{$\begin{array}{c}\mathrm{H}_{2} \mathrm{O} \text { quente } \\
20 \mathrm{~min}\end{array}$} & \multicolumn{3}{|c|}{$\mathrm{H}_{2} \mathrm{SO}_{4}$} \\
\hline & & & & $40 \mathrm{~min}$ & $60 \mathrm{~min}$ & $80 \mathrm{~min}$ \\
\hline 1 & 6,1 & 7,6 & 5,5 & 13,9 & 9,8 & 12,2 \\
\hline 2 & 6,0 & 9,5 & 5,8 & 13,7 & 11,6 & 10,3 \\
\hline 3 & 5,7 & 9,3 & 6,4 & 13,6 & 10,0 & 10,5 \\
\hline 4 & 5,1 & 7,6 & 6,9 & 12,9 & 11,9 & 10,2 \\
\hline 5 & 6,0 & 9,3 & 7,1 & 10,5 & 11,2 & 10,1 \\
\hline 6 & 5,9 & 9,1 & 7,7 & 12,0 & 11,4 & 11,3 \\
\hline 7 & 6,8 & 8,8 & 8,7 & 12,1 & 11,9 & 12,6 \\
\hline Média & 5,9 & 8,7 & 6,9 & 12,7 & 11,1 & 11,0 \\
\hline $\begin{array}{l}\text { Diferença entre o } \\
\text { maior e o menor valor }\end{array}$ & 1,7 & 1,9 & 3,2 & 2,4 & 2,1 & 2,5 \\
\hline
\end{tabular}

R. Árvore, Viçosa-MG, v.32, n.6, p.1059-1067, 2008 
Quadro 2 - Vigor avaliado pelos testes de primeira contagem (PC), índice de velocidade de emergência (IVE) e condutividade elétrica (CE) de sete lotes de sementes de Stryphnodendron adstringens, após tratamentos de superação de dormência

Table 2 - Seed vigor evaluated by first counting of germination test (PC), germination rate (IVE) and conductivity test (CE) of seven seed lots of Stryphnodendron adstringens after breaking dormancy treatments

\begin{tabular}{|c|c|c|c|c|c|c|c|}
\hline \multirow{3}{*}{$\begin{array}{l}\text { Testes de } \\
\text { Vigor }\end{array}$} & \multirow[t]{3}{*}{ Lotes } & \multicolumn{5}{|c|}{ Tratamentos de Superação de Dormência } & \\
\hline & & \multirow[t]{2}{*}{ Testemunha } & \multirow[t]{2}{*}{ Lixa } & \multirow{2}{*}{$\begin{array}{c}\mathrm{H}_{2} \mathrm{O} \text { quente } \\
20 \mathrm{~min}\end{array}$} & \multicolumn{3}{|c|}{$\mathrm{H}_{2} \mathrm{SO}_{4}$} \\
\hline & & & & & $40 \min$ & $60 \mathrm{~min}$ & $80 \mathrm{~min}$ \\
\hline \multirow{8}{*}{$\mathrm{PC}(\%)^{1}$} & 1 & $0,0 \mathrm{Da}$ & $46,0 \mathrm{Bbc}$ & $3,0 \mathrm{Cb}$ & $41,0 \mathrm{Bc}$ & $60,0 \mathrm{Ad}$ & $59,0 \mathrm{Ac}$ \\
\hline & 2 & $0,0 \mathrm{Da}$ & $48,0 \mathrm{Bbc}$ & $6,0 \mathrm{Ca}$ & $53,0 \mathrm{Bb}$ & $70,0 \mathrm{Abcd}$ & $58,0 \mathrm{ABc}$ \\
\hline & 3 & $0,0 \mathrm{Ea}$ & $42,0 \mathrm{Cc}$ & 3,0 Dab & $58,0 \mathrm{Bab}$ & $69,0 \mathrm{ABcd}$ & $73,0 \mathrm{Aab}$ \\
\hline & 4 & $0,0 \mathrm{Ca}$ & $63,0 \mathrm{Ba}$ & $2,0 \mathrm{Cb}$ & $69,0 \mathrm{ABa}$ & 80,0 Aabc & $80,0 \mathrm{Aa}$ \\
\hline & 5 & $0,0 \mathrm{Ca}$ & $57,0 \mathrm{Bab}$ & $2,0 \mathrm{Cb}$ & $66,0 \mathrm{Ba}$ & $84,0 \mathrm{Aab}$ & $67,0 \mathrm{Babc}$ \\
\hline & 6 & $0,0 \mathrm{Da}$ & $52,0 \mathrm{Cabc}$ & $2,0 \mathrm{Db}$ & $60,0 \mathrm{BCab}$ & $86,0 \mathrm{Aa}$ & $65,0 \mathrm{Bbc}$ \\
\hline & 7 & $0,0 \mathrm{Da}$ & $42,0 \mathrm{Bc}$ & $2,0 \mathrm{Cb}$ & $48,0 \mathrm{Bbc}$ & $65,0 \mathrm{Ad}$ & $77,0 \mathrm{Aab}$ \\
\hline & CV\% & 7,0 & & & & & \\
\hline \multirow{8}{*}{ IVE } & 1 & $0,3 \mathrm{Cb}$ & $8,1 \mathrm{ABc}$ & $1,0 \mathrm{Cab}$ & $7,7 \mathrm{Bcd}$ & 9,3 Abc & $9,1 \mathrm{Abc}$ \\
\hline & 2 & $0,2 \mathrm{Cb}$ & $7,1 \mathrm{Bcd}$ & $1,2 \mathrm{Cab}$ & $8,4 \mathrm{Abc}$ & $9,4 \mathrm{Abc}$ & $8,7 \mathrm{Ac}$ \\
\hline & 3 & $0,2 \mathrm{Cb}$ & $7,8 \mathrm{Bcd}$ & $0,7 \mathrm{Cb}$ & $9,3 \mathrm{Aab}$ & $9,5 \mathrm{Abc}$ & $10,2 \mathrm{Aab}$ \\
\hline & 4 & $0,2 \mathrm{Cb}$ & $9,4 \mathrm{Bab}$ & $0,6 \mathrm{Cb}$ & $9,6 \mathrm{Bab}$ & $10,4 \mathrm{ABab}$ & $10,9 \mathrm{Aa}$ \\
\hline & 5 & $0,3 \mathrm{Db}$ & $9,8 \mathrm{BCa}$ & $0,3 \mathrm{Db}$ & $10,0 \mathrm{ABa}$ & $11,1 \mathrm{Aa}$ & $8,6 \mathrm{Cc}$ \\
\hline & 6 & $0,9 \mathrm{Cb}$ & $8,3 \mathrm{Bbc}$ & $1,6 \mathrm{Cab}$ & 9,2 Bab & $10,9 \mathrm{Aa}$ & 9,4 Bbc \\
\hline & 7 & $2,3 \mathrm{Da}$ & $6,7 \mathrm{Cd}$ & $2,1 \mathrm{Da}$ & $6,7 \mathrm{Cd}$ & $8,2 \mathrm{Bc}$ & $10,3 \mathrm{Aab}$ \\
\hline & CV\% & 9,9 & & & & & \\
\hline \multirow{8}{*}{$\begin{array}{l}\mathrm{CE} \\
\left(\mathrm{uS} \cdot \mathrm{cm}^{-1} \cdot \mathrm{g}^{-1}\right)\end{array}$} & 1 & $4,7 \mathrm{Aa}$ & $63,9 \mathrm{Ca}$ & $3,2 \mathrm{Aa}$ & $37,7 \mathrm{Ba}$ & $61,4 \mathrm{Ca}$ & $58,1 \mathrm{BCa}$ \\
\hline & 2 & 5,3 Aa & $65,9 \mathrm{Ba}$ & 2,9 Aa & $63,9 \mathrm{Bb}$ & $54,1 \mathrm{Ba}$ & $58,0 \mathrm{Ba}$ \\
\hline & 3 & $3,2 \mathrm{Aa}$ & $70,2 \mathrm{Ba}$ & $2,6 \mathrm{Aa}$ & $52,4 \mathrm{Bab}$ & $57,6 \mathrm{Ba}$ & $59,1 \mathrm{Ba}$ \\
\hline & 4 & $5,2 \mathrm{Aa}$ & $62,9 \mathrm{Ba}$ & 5,6 Aab & $46,9 \mathrm{Bab}$ & $54,7 \mathrm{Ba}$ & $44,6 \mathrm{Ba}$ \\
\hline & 5 & 4,4 Aa & $74,9 \mathrm{Ca}$ & $6,4 \mathrm{Aab}$ & $47,1 \mathrm{Bab}$ & $59,1 \mathrm{BCa}$ & $62,7 \mathrm{BCa}$ \\
\hline & 6 & $15,2 \mathrm{Aa}$ & $75,3 \mathrm{Ca}$ & $25,8 \mathrm{Ab}$ & $48,0 \mathrm{Bab}$ & $64,9 \mathrm{BCa}$ & $52,2 \mathrm{Ba}$ \\
\hline & 7 & $51,9 \mathrm{Bb}$ & $126,1 \mathrm{Cb}$ & 3,6 Aab & $114,3 \mathrm{Cc}$ & $112,6 \mathrm{Cb}$ & $155,9 \mathrm{Db}$ \\
\hline & CV\% & 21,8 & & & & & \\
\hline
\end{tabular}

Em cada característica avaliada, médias seguidas pela mesma letra, minúscula na coluna e maiúscula na linha, não diferem estatisticamente entre si, pelo teste de Tukey $(\mathrm{P}<0,05)$. 1 - Os dados foram transformados em $(\mathrm{x}+0,5)^{1 / 2}$, sendo as médias apresentadas dos valores originais.

Houve comportamento diferenciado entre os lotes em resposta aos tratamentos de imersão em ácido sulfúrico. O lote 7, embora tenha tido a dormência superada pelos períodos de 40 a 80 min de imersão, apresentou, respectivamente, menor e maior porcentagem de plântulas normais nesses extremos de tempo de imersão, exibindo resultados intermediários e que não diferiram dos obtidos aos $60 \mathrm{~min}$. No lote 5, a imersão por $80 \mathrm{~min}$ parece ter sido excessiva por ter elevado a porcentagem de sementes mortas e reduzido à de plântulas normais, embora tenha superado totalmente a dormência das sementes, de forma similar aos demais tempos de imersão e, neste lote, o tempo de imersão deveria ser de até 60 min.

O tratamento de imersão em água quente por 20 min foi o de menor eficiência entre os testados, somente superando significativamente a porcentagem de sementes dormentes dos lotes 1 e 2 (Quadro 3). Esses resultados indicaram que os lotes podem responder, de forma diversa, a esse tratamento, havendo alguns nos quais a dormência é superada de forma mais eficiente que outros e em que a germinação é incrementada. Os resultados concordam com os obtidos por Borges et al. (2004) ema sementes de Tachigalia multijuga, que observaram que diferentes genótipos podem apresentar variação na eficiência da resposta a tratamentos de superação de dormência.

Em valores médios de germinação, a testemunha apresentou $12 \%$, a escarificação com lixa $78 \%$, a imersão em água quente $18 \%$ e a imersão em ácido sulfúrico por 40, 60 e $80 \mathrm{~min}$ apresentou 82,83 e $84 \%$, respectivamente. Em valores médios de dormência, a testemunha exibiu $76 \%$, a escarificação com lixa $10 \%$, a imersão em água quente $68 \%$ e a imersão em ácido sulfúrico por 40, 60 e $80 \mathrm{~min}$ apresentou 2, 0 e $0 \%$, respectivamente. Em trabalhos com sementes de Senna macranthera (SANTARÉM e AQUILA, 1995), Enterolobium contortisiliquum (EIRA et al., 1993), 
Leucaena leucocephala (NUNÕ, 1995) e Tachigalia multijuga (BORGES et al., 2004), o tratamento com água quente promoveu a superação da dormência e a germinação em valores inferiores aos obtidos com ácido sulfúrico. Adicionalmente, o tratamento com ácido sulfúrico tem sido citado por vários autores como um dos mais promissores na superação da dormência de sementes de várias espécies que apresentam dureza tegumentar (ALCALAY e AMARAL, 1982; EIRA et al., 1993; TORRES e SANTOS, 1994; RIBAS et al., 1996; JELLER e PEREZ, 1999; BORGES et al., 2004; ALVES et al., 2006), inclusive de Stryphnodendron pulcherrimum (VARELA et al., 1991).

Quanto ao comprimento de raiz e total da plântula (Quadro 4), a escarificação com lixa não promoveu resultados melhores que a testemunha, divergindo dos resultados anteriormente verificados de condutividade elétrica, primeira contagem de germinação, índice de velocidade de emergência, sementes dormentes e plântulas normais (Quadros 2 e 3); e isso em todos os lotes, exceto no 3 quanto ao comprimento total de plântula (Quadro 4). Isso pode ser atribuído ao fato de a escarificação com lixa ser realizada na semente do lado oposto da radícula. Assim, o tegumento permanece impermeável nas regiões circunvizinhas dessa estrutura, podendo dificultar a difusão da água dentro da semente até chegar à região da radícula, retardando esse processo; ou mesmo oferecer resistência mecânica ao crescimento da raiz. O fato de o comprimento da parte aérea nos lotes 1, 2, 3 e 5 ter sido maior que a testemunha corrobora essa hipótese, pois o epicótilo e o hipocótilo estavam mais próximos da região da casca que foi lixada do que a radícula.

Quadro 3 - Porcentagem de plântulas normais, anormais, sementes dormentes e mortas de sete lotes de sementes de Stryphnodendron adstringens após tratamentos de superação de dormência

Table 3 - Percentage of normal and abnormal seedlings, dormant and dead seeds of seven seed lots of Stryphnodendron adstringens, after breaking dormancy treatments

\begin{tabular}{|c|c|c|c|c|c|c|c|}
\hline \multirow{3}{*}{$\begin{array}{l}\text { Parâmetros } \\
(\%)\end{array}$} & \multirow[t]{3}{*}{ Lotes } & \multicolumn{5}{|c|}{ Tratamentos de Superação de Dormência } & \\
\hline & & \multirow[t]{2}{*}{ Testemunha } & \multirow[t]{2}{*}{ Lixa } & \multirow{2}{*}{$\begin{array}{c}\mathrm{H}_{2} \mathrm{O} \text { quente } \\
20 \mathrm{~min} \\
\end{array}$} & \multicolumn{3}{|c|}{$\mathrm{H}_{2} \mathrm{SO}_{4}$} \\
\hline & & & & & $40 \mathrm{~min}$ & $60 \mathrm{~min}$ & $80 \mathrm{~min}$ \\
\hline & 1 & $6,0 \mathrm{Cc}$ & $80,5 \mathrm{Aab}$ & $21,5 \mathrm{Babc}$ & $81,5 \mathrm{Aa}$ & $88,0 \mathrm{Aa}$ & $85,0 \mathrm{Aab}$ \\
\hline & 2 & $4,5 \mathrm{Cc}$ & $63,5 \mathrm{Ab}$ & $19,0 \mathrm{Bbc}$ & $81,5 \mathrm{Aa}$ & $79,0 \mathrm{Aab}$ & $79,5 \mathrm{Aab}$ \\
\hline Plântulas & 3 & $5,5 \mathrm{Cc}$ & 78,5 Aab & $13,5 \mathrm{Bc}$ & $87,0 \mathrm{Aa}$ & $81,5 \mathrm{Aab}$ & 90,5 Аа \\
\hline \multirow[t]{7}{*}{ normais } & 4 & $5,5 \mathrm{Cc}$ & $85,5 \mathrm{Aa}$ & $13,0 \mathrm{Bc}$ & 83,0 Aa & $86,5 \mathrm{Aa}$ & $92,5 \mathrm{Aa}$ \\
\hline & 5 & $8,0 \mathrm{Cc}$ & $95,0 \mathrm{Aa}$ & $5,0 \mathrm{Cd}$ & 94,0 Aa & $92,5 \mathrm{Aa}$ & $69,5 \mathrm{Bb}$ \\
\hline & 6 & $21,0 \mathrm{Bb}$ & $78,5 \mathrm{Aab}$ & $25,5 \mathrm{Bab}$ & $84,5 \mathrm{Aa}$ & $88,0 \mathrm{Aa}$ & $85,0 \mathrm{Aab}$ \\
\hline & 7 & $33,0 \mathrm{Ca}$ & $62,5 \mathrm{Bb}$ & $30,0 \mathrm{Ca}$ & $59,5 \mathrm{Bb}$ & $67,0 \mathrm{ABb}$ & $86,0 \mathrm{Aab}$ \\
\hline & CV\% & 7,2 & & & & & \\
\hline & 1 & $0,0 \mathrm{Aa}$ & $1,0 \mathrm{Aa}$ & $0,5 \mathrm{Aa}$ & 0,0 Aa & $1,5 \mathrm{Aa}$ & $2,5 \mathrm{Aab}$ \\
\hline & 2 & $1,0 \mathrm{Aa}$ & $0,5 \mathrm{Aa}$ & 0,5 Aa & 1,0 Aa & $1,5 \mathrm{Aa}$ & 1,0 Aab \\
\hline Plântulas & 3 & $0,5 \mathrm{Aa}$ & 0,0 Aa & 0,5 Aa & $0,5 \mathrm{Aa}$ & $1,5 \mathrm{Aa}$ & $0,5 \mathrm{Ab}$ \\
\hline \multirow[t]{7}{*}{ anormais $^{1}$} & 4 & $0,5 \mathrm{Aa}$ & $0,5 \mathrm{Aa}$ & $1,5 \mathrm{Aa}$ & $1,5 \mathrm{Aa}$ & $1,5 \mathrm{Aa}$ & $0,5 \mathrm{Ab}$ \\
\hline & 5 & $0,5 \mathrm{Aa}$ & $0,5 \mathrm{Aa}$ & $0,5 \mathrm{Aa}$ & $2,0 \mathrm{Aa}$ & $0,0 \mathrm{Aa}$ & $2,0 \mathrm{Aab}$ \\
\hline & 6 & $0,5 \mathrm{Ba}$ & $0,5 \mathrm{Ba}$ & $0,5 \mathrm{Ba}$ & $2,0 \mathrm{ABa}$ & $0,0 \mathrm{Ba}$ & $4,5 \mathrm{Aa}$ \\
\hline & 7 & 0,0 Aa & $0,5 \mathrm{Aa}$ & $1,0 \mathrm{Aa}$ & $2,0 \mathrm{Aa}$ & $3,0 \mathrm{Aa}$ & $1,5 \mathrm{Aab}$ \\
\hline & $\mathrm{CV} \%$ & 49,9 & & & & & \\
\hline & 1 & $84,5 \mathrm{Aa}$ & $8,0 \mathrm{Cc}$ & $69,5 \mathrm{Bbc}$ & $12,0 \mathrm{Ca}$ & $0,5 \mathrm{Da}$ & $0,0 \mathrm{Da}$ \\
\hline & 2 & $89,0 \mathrm{Aa}$ & $29,5 \mathrm{Ca}$ & $70,5 \mathrm{Bbc}$ & $1,0 \mathrm{Db}$ & $0,0 \mathrm{Da}$ & $0,0 \mathrm{Da}$ \\
\hline Sementes & 3 & $92,5 \mathrm{Aa}$ & $18,5 \mathrm{Bb}$ & 79,0 Aab & $0,0 \mathrm{Cb}$ & $0,0 \mathrm{Ca}$ & $0,0 \mathrm{Ca}$ \\
\hline \multirow{7}{*}{ dormentes $^{1}$} & 4 & $79,5 \mathrm{Aab}$ & $2,5 \mathrm{Bd}$ & $76,0 \mathrm{Aab}$ & $0,5 \mathrm{BCb}$ & $0,0 \mathrm{Ca}$ & $0,0 \mathrm{Ca}$ \\
\hline & 5 & $88,0 \mathrm{Aa}$ & $0,5 \mathrm{Bd}$ & $90,5 \mathrm{Aa}$ & $0,0 \mathrm{Bb}$ & $0,0 \mathrm{Ba}$ & $0,0 \mathrm{Ba}$ \\
\hline & 6 & $66,5 \mathrm{Ab}$ & $8,5 \mathrm{Bc}$ & $60,0 \mathrm{Ac}$ & $0,0 \mathrm{Cb}$ & $0,0 \mathrm{Ca}$ & $0,0 \mathrm{Ca}$ \\
\hline & 7 & $31,5 \mathrm{Ac}$ & $1,0 \mathrm{Bd}$ & $29,0 \mathrm{Ad}$ & $0,0 \mathrm{Bb}$ & $0,0 \mathrm{Ba}$ & $0,0 \mathrm{Ba}$ \\
\hline & $\mathrm{CV} \%$ & 11,2 & & & & & \\
\hline & 1 & $9,5 \mathrm{Abc}$ & $10,5 \mathrm{Abc}$ & $8,5 \mathrm{Abc}$ & $6,5 \mathrm{Abc}$ & $10,0 \mathrm{Ab}$ & $12,5 \mathrm{Aabc}$ \\
\hline & 2 & 5,5 Cbcd & $6,5 \mathrm{BCbc}$ & $10,0 \mathrm{ABCbc}$ & $16,5 \mathrm{ABb}$ & $19,5 \mathrm{Aab}$ & $19,5 \mathrm{Aab}$ \\
\hline Sementes & 3 & 1,5 Dd & 3,0 CDc & 7,0 BCDbc & $12,5 \mathrm{ABb}$ & $17,0 \mathrm{Aab}$ & $9,0 \mathrm{ABCbc}$ \\
\hline \multirow[t]{5}{*}{ mortas } & 4 & $14,5 \mathrm{Ab}$ & $11,5 \mathrm{Abc}$ & $9,5 \mathrm{Abc}$ & $15 \mathrm{Ab}$ & $12,0 \mathrm{Ab}$ & 7,0 Ac \\
\hline & 5 & $3,5 \mathrm{Bcd}$ & $4,0 \mathrm{Bbc}$ & $4,0 \mathrm{Bc}$ & $4,0 \mathrm{Bc}$ & $7,5 \mathrm{Bb}$ & $28,5 \mathrm{Aa}$ \\
\hline & 6 & $12,0 \mathrm{Abc}$ & $12,5 \mathrm{Ab}$ & $14,0 \mathrm{Ab}$ & $13,5 \mathrm{Ab}$ & $12,0 \mathrm{Ab}$ & $10,5 \mathrm{Abc}$ \\
\hline & 7 & $35,5 \mathrm{Aa}$ & $36,0 \mathrm{Aa}$ & $40,0 \mathrm{Aa}$ & $38,5 \mathrm{Aa}$ & $30,0 \mathrm{Aa}$ & $12,5 \mathrm{Bbc}$ \\
\hline & $\mathrm{CV} \%$ & 22.4 & & & & & \\
\hline
\end{tabular}

Em cada característica avaliada, médias seguidas pela mesma letra, minúscula na coluna e maiúscula na linha, não diferem estatisticamente entre si, pelo teste de Tukey $(\mathrm{P}<0,05)$. 1 - Os dados foram transformados em $(\mathrm{x}+0,5)^{1 / 2}$, sendo as médias apresentadas dos valores originais. 
Quadro 4-Vigor de plântulas avaliado pelo comprimento de raiz, parte aérea e total de sete lotes de sementes de Stryphnodendron adstringens, após tratamentos de superação de dormência

Table 4 - Seedling vigor evaluated by root, shoot and total length of seven seed lots of Stryphnodendron adstringens after breaking dormancy treatments

\begin{tabular}{|c|c|c|c|c|c|c|c|}
\hline \multirow{3}{*}{$\begin{array}{l}\text { Comprimento } \\
\text { de Plântulas } \\
(\mathrm{cm})\end{array}$} & \multirow[t]{3}{*}{ Lotes } & \multicolumn{5}{|c|}{ Tratamentos de Superação de Dormência } & \\
\hline & & \multirow[t]{2}{*}{ Testemunha } & \multirow[t]{2}{*}{ Lixa } & \multirow{2}{*}{$\begin{array}{c}\mathrm{H}_{2} \mathrm{O} \text { quente } \\
20 \mathrm{~min}\end{array}$} & \multicolumn{3}{|c|}{$\mathrm{H}_{2} \mathrm{SO}_{4}$} \\
\hline & & & & & $40 \mathrm{~min}$ & $60 \mathrm{~min}$ & $80 \mathrm{~min}$ \\
\hline \multirow{8}{*}{ Raiz } & 1 & $1.1 \mathrm{Bbc}$ & $3.5 \mathrm{ABa}$ & $4.0 \mathrm{ABb}$ & $7.1 \mathrm{Aa}$ & $7.0 \mathrm{Aab}$ & $2.1 \mathrm{Bc}$ \\
\hline & 2 & $2.1 \mathrm{Cbc}$ & $2.9 \mathrm{BCa}$ & $2.4 \mathrm{Cb}$ & $6.3 \mathrm{ABab}$ & $7.6 \mathrm{Aa}$ & $3.2 \mathrm{BCc}$ \\
\hline & 3 & $0.0 \mathrm{Cc}$ & $3.0 \mathrm{BCa}$ & $8.5 \mathrm{Aa}$ & $6.3 \mathrm{ABab}$ & 7.4 Aab & $2.6 \mathrm{BCc}$ \\
\hline & 4 & $3.8 \mathrm{BCabc}$ & $4.6 \mathrm{BCa}$ & $3.0 \mathrm{Cb}$ & $6.7 \mathrm{ABa}$ & $9.0 \mathrm{Aa}$ & $9.8 \mathrm{Aa}$ \\
\hline & 5 & $2.4 \mathrm{Cbc}$ & $4.7 \mathrm{BCa}$ & $1.1 \mathrm{Cb}$ & 6.6 ABab & 7.7 ABa & $9.6 \mathrm{Aab}$ \\
\hline & 6 & 4.8 ABab & $4.5 \mathrm{ABa}$ & $4.1 \mathrm{Bb}$ & $4.8 \mathrm{ABab}$ & $6.9 \mathrm{ABab}$ & $7.9 \mathrm{Aab}$ \\
\hline & 7 & $6.6 \mathrm{Aa}$ & $3.6 \mathrm{ABa}$ & $4.6 \mathrm{ABb}$ & $2.8 \mathrm{Bb}$ & $3.5 \mathrm{ABb}$ & $5.7 \mathrm{ABbc}$ \\
\hline & $\mathrm{CV} \%$ & 37.4 & & & & & \\
\hline \multirow{8}{*}{ Parte aérea } & 1 & $2.0 \mathrm{Cbc}$ & $6.6 \mathrm{ABa}$ & $1.6 \mathrm{Cb}$ & 8.0 Aab & $9.2 \mathrm{Aab}$ & $3.6 \mathrm{BCc}$ \\
\hline & 2 & $1.4 \mathrm{Cc}$ & $6.3 \mathrm{ABa}$ & $2.2 \mathrm{BCb}$ & $8.8 \mathrm{Aa}$ & 9.9 Aa & 7.4 Aabc \\
\hline & 3 & $0.0 \mathrm{Cc}$ & $4.8 \mathrm{Ba}$ & $6.6 \mathrm{ABa}$ & $8.1 \mathrm{ABab}$ & $9.3 \mathrm{Aab}$ & $4.2 \mathrm{Bbc}$ \\
\hline & 4 & $6.0 \mathrm{ABab}$ & $6.6 \mathrm{ABa}$ & $3.2 \mathrm{Bab}$ & $8.6 \mathrm{Aab}$ & $10.0 \mathrm{Aa}$ & $9.7 \mathrm{Aa}$ \\
\hline & 5 & $2.3 \mathrm{Bbc}$ & $7.1 \mathrm{Aa}$ & $0.5 \mathrm{Bb}$ & $8.7 \mathrm{Aa}$ & 9.4 Aab & $8.5 \mathrm{Aa}$ \\
\hline & 6 & $6.9 \mathrm{Aa}$ & $7.3 \mathrm{Aa}$ & $6.5 \mathrm{Aa}$ & 8.5 Aab & 9.1 Aab & $8.1 \mathrm{Aab}$ \\
\hline & 7 & $8.0 \mathrm{Aa}$ & $5.4 \mathrm{Aa}$ & $6.5 \mathrm{Aa}$ & $4.4 \mathrm{Ab}$ & $5.6 \mathrm{Ab}$ & 6.2 Aabc \\
\hline & CV\% & 32.0 & & & & & \\
\hline \multirow{8}{*}{ Total } & 1 & $3.1 \mathrm{Bcd}$ & $10.1 \mathrm{ABa}$ & $5.6 \mathrm{Bbc}$ & $15.1 \mathrm{Aa}$ & 16.1 Aab & $5.6 \mathrm{Bc}$ \\
\hline & 2 & $3.6 \mathrm{Ccd}$ & $9.1 \mathrm{BCa}$ & $4.6 \mathrm{Cbc}$ & 15.0 Aba & $17.5 \mathrm{Aa}$ & $10.6 \mathrm{ABCbc}$ \\
\hline & 3 & $0.0 \mathrm{Dd}$ & $7.8 \mathrm{BCa}$ & $15.1 \mathrm{ABa}$ & $14.4 \mathrm{ABab}$ & 16.6 Aab & $6.9 \mathrm{CDc}$ \\
\hline & 4 & $9.8 \mathrm{BCabc}$ & $11.1 \mathrm{BCa}$ & $6.2 \mathrm{Cbc}$ & 15.3 Aba & $19.1 \mathrm{Aa}$ & $19.5 \mathrm{Aa}$ \\
\hline & 5 & 4.7 BCbcd & $11.8 \mathrm{ABa}$ & $1.5 \mathrm{Cc}$ & $15.3 \mathrm{Aa}$ & 17.1 Aa & $18.0 \mathrm{Aab}$ \\
\hline & 6 & $11.7 \mathrm{Aab}$ & $11.7 \mathrm{Aa}$ & $10.6 \mathrm{Aab}$ & 13.2 Aab & $16.0 \mathrm{Aab}$ & 16.1 Aab \\
\hline & 7 & $14.6 \mathrm{Aa}$ & $9.0 \mathrm{Aa}$ & $11.1 \mathrm{Aab}$ & $7.2 \mathrm{Ab}$ & $9.1 \mathrm{Ab}$ & 11.9 Aabc \\
\hline & CV\% & 11.1 & & & & & \\
\hline
\end{tabular}

Em cada característica avaliada, médias seguidas pela mesma letra, minúscula na coluna e maiúscula na linha, não diferem estatisticamente entre si, pelo teste de Tukey $(\mathrm{P}<0,05)$.

O tratamento com água quente por 20 min não afetou o crescimento de plântulas da quase totalidade dos lotes, exceção feita ao lote 3 , que foi o único favorecido, apresentando maior comprimento de raiz, parte aérea e total quando comparado com a testemunha.

Os lotes 6 e 7 não mostraram efeito de nenhum dos tratamentos sobre o comprimento de plântulas, talvez pelo fato de esses lotes originalmente já apresentarem menor porcentagem de sementes dormentes que os demais e maiores de plântulas normais, como se pode comprovar no tratamentotestemunha (Quadro 3). Portanto, talvez a impermeabilidade do tegumento não fosse tão intensa que deixasse em evidência o efeito favorável dos tratamentos de superação de dormência sobre o crescimento das plântulas

Com exceção dos lotes 6 e 7, na maioria dos lotes observou-se, assim, que o tratamento de escarificação em ácido sulfúrico por 40 e $60 \mathrm{~min}$ favoreceu o crescimento de plântulas, que possibilitou maior crescimento total, da parte aérea e da raiz, em comparação com a testemunha. A escarificação por 80 min somente apresentou resultados mais favoráveis que a testemunha em poucos lotes, ou seja: nos lotes 2 e 3, quanto à parte aérea; e lotes 4 e 5, no comprimento total e da raiz. A escarificação em ácido sulfúrico por $60 \mathrm{~min}$ apresentou comprimento da raiz e total superior, inclusive, em relação ao tratamento de lixa em três dos lotes avaliados (lotes 2, 3 e 4) (Quadro 4).

Por esses resultados, verifica-se que a escarificação em ácido sulfúrico (PA) por 60 min foi o tratamento mais eficiente para superar a dormência, acelerar e aumentar a porcentagem de germinação e resultar plântulas de maior tamanho nas sementes de diferentes locais de origem.

R. Árvore, Viçosa-MG, v.32, n.6, p.1059-1067, 2008 


\section{CONCLUSÃO}

A escarificação em ácido sulfúrico por 60 min é o método mais promissor para a superação de dormência de sementes de barbatimão.

\section{REFERÊNCIAS}

ALCALAY, N.; AMARAL, D. M. I. Quebra de dormência em sementes de timbaúba (Enterolobium contortisiliquum(Vell.) Morong.). Silvicultura em São Paulo, v.16A, n.1, pt.2, p.1149-1152, 1982. (Edição Especial).

ALVES, M. C. S. et al. Superação da dormência em sementes de Bauhinia monandra Brit. ou

Bauhinia ungulata L. - Caesalpinoideae.

Revista Brasileira de Sementes, v.22, n.2, p.139-144, 2000.

ALVES, E. U. et al. Ácido sulfúrico superação da dormência de unidade de dispersão de juazeiro (Zizyphus joazeiro Mart.). Revista Árvore, v.30, n.2, p.187-195, 2006.

BARBIN, D. Planejamento e análise de experimentos agronômicos. Arapongas: Midas, 2003. 208p.

BORGES, E. E. L. et al. Alterações fisiológicas em sementes de Tachigalia multijuga (Benth.) (mamoneira) relacionadas aos métodos para a superação da dormência. Revista Árvore, v.28, n.3, p.317-325, 2004.

BRASIL. Ministério da Agricultura e da Reforma Agrária Regras para análise de sementes. Brasília: SNDA/DNDV/CLAV, 1992.365p.

BRUNO, R. L. A. et al. Tratamentos para superar a dormência de sementes de sabiá. Revista Brasileira de Sementes, v.23, n.2, p.136-143, 2001.

CARVAlho, N. M.; NAKAGAWA, J. Sementes: ciência, tecnologia e produção. 4.ed. Jaboticabal: FUNEP, 2000. 588p.

EIRA, M. T. S.; FREITAS, R. W. A.; MELLO, C. M. C. Superação de dormência de sementes de Enterolobium contortisiliquum (Vell.) Morong.Leguminosae. Revista Brasileira de Sementes, v.15, n.2, p.177-181, 1993.

R. Árvore, Viçosa-MG, v.32, n.6, p.1059-1067, 2008
FELFILI, J. M.; SILVA JÚNIOR, M. C. A comparative study of cerrado (sensu stricto) vegetation in central Brazil. Journal of Tropical Ecology, v.9, n.3, p.277-289, 1993.

FELFILI, J. M. et al. Estudo fenológico de Stryphnodendron adstringens (Mart.) Coville no cerrado sensu stricto da Fazenda Água Limpa no Distrito Federal, Brasil. Revista Brasileira de Botânica, v.22, n.1, p.83-90, 1999.

JELLER, H.; PEREZ, S. C. J. G. A. Estudo da superação da dormência e da temperatura em sementes de Cassia excelsa Schrad. Revista Brasileira de Sementes, v.21, n.1, p.32-40, 1999.

LEMUS FILHO, J. P. et al. Germinação de sementes de Senna macranthera, Senna multijuga e Stryphnodendron polyphyllum. Pesquisa Agropecuária Brasileira, v.32, n.4, p.357-361, 1997.

LORENZI, H. Árvores brasileiras: manual de identificação e cultivo de plantas arbóreas nativas do Brasil. Nova Odessa: Instituto Plantarum, 1992. v.1.373p.

MAGUIRE, J. D. Speed of germination as aid in selection and evaluation for emergence and vigour. Crop Science, v.2, p.176-177, 1962.

MARTINS, C. C.; MACHADO, C. G.; NAKAGAWA, J. Temperatura e substrato para o teste de germinação de sementes de barbatimão (Stryphnodendron adstringens (Mart.) Coville (Leguminosae). Revista Árvore, v.32, n.4, p.633-639, 2008.

NUNÕ, R. V. Estudo de características físicas e fisiológicas de sementes de leucena (Leucaena leucocephala (Lam.) de wit). 1995. 106f. Tese (Doutorado) - Escola Superior de Agricultura "Luiz de Queiroz", Piracicaba, 1995.

POPINIGIS, F. Fisiologia de sementes. 2.ed. Brasília: ABRATES, 1985. 298p.

RIBAS, L. L. F.; FOSSATI, L. C.; NOGUEIRA, A. C. Superação de dormência de sementes de Mimosa bimucronata (DC.) O. Kuntze (maricá). Revista Brasileira de Sementes, v.18, n.1, p.98-101, 1996. 
SANTARÉM, E. R.; ÁQUILA, M. E. A. Influência de métodos de superação de dormência e do armazenamento na germinação de sementes de Senna mancranthera (Colladon) Irwin E Barneby (Leguminosae). Revista Brasileira de Sementes, v.17, n.2, p.205-209, 1995.

TORRES, S. B.; SANTOS, S. S. B. Superação de dormência em sementes de Acacia senegal (L.) Willd. e Parkisonia aculeata L. Revista Brasileira de Sementes, v.16, n.1, p.54-57, 1994.
VARELA, V. P.; BROCKI, E.; SÁ, S. T. V. Tratamentos pré-germinativos de semente de espécies florestais da Amazônia: IV. Faveira camuzê - Stryphnodendron pulcherrimum (Willd.) Hochr Leguminosae. Revista Brasileira de Sementes, v.13, n.2, p.87-90, 1991.

VIEIRA, R. D.; CARVALHO, N. M. Testes de vigor em sementes. Jaboticabal: FUNEP, 1994. v.1. 164p. 